Supporting Information

\title{
A gyroidal MOF with unprecedented interpenetrating utc-c network exhibiting exceptional thermal stability and ultrahigh $\mathrm{CO}_{2}$ affinity
}

Wei Xu, ${ }^{\dagger}$ Yin-Jiang Tang, ${ }^{\dagger}$ Lian-Qing Zheng, ${ }^{\dagger}$ Jia-Ming Xu, ${ }^{\dagger}$ Jian-Zhong Wu, ${ }^{*},{ }^{\dagger}$ Yong-Cong $\mathrm{Ou}^{*}, \dagger$ and Ming-Liang Tong ${ }^{\ddagger}$

$\dagger$ School of Chemistry, South China Normal University, Guangzhou 510006, China. Email:ouyongcong@m.scnu.edu.cn,wujzh@scnu.edu.cn

$\$$ MOE Key Laboratory of Bioinorganic and Synthetic Chemistry, School of Chemistry, Sun Yet-Sen University, Guangzhou 501275, China. 


\section{Experimental section:}

\section{Materials and Physical Measurements}

The reagents and solvents employed were commercially available and used as received without further purification. The $\mathrm{C}, \mathrm{H}$, and $\mathrm{N}$ microanalyses were carried out with an Elementar Vario-EL CHNS elemental analyzer. The FT-IR spectra were recorded from $\mathrm{KBr}$ pellets in the range 4000-400 $\mathrm{cm}^{-1}$ on a PerkinElmer spectrometer. Powder X-ray diffraction (PXRD) intensities for polycrystalline samples were measured at $293 \mathrm{~K}$ on Rigaku Ultima IV Diffratometer $\left(\mathrm{Cu}-\mathrm{K}_{\alpha}, \lambda=\right.$ $1.54056 \AA$ ) by scanning over the range of $3-50^{\circ}$ with step of $0.2^{\circ} / \mathrm{s}$. Calculated patterns were generated with Mercury. TGA data were obtained on a NETZSCH TG 209 F3 Analyzer, with a heating rate of $10{ }^{\circ} \mathrm{C} \mathrm{min}-1$ in nitrogen/air atmosphere. ${ }^{1} \mathrm{H}$ spectra were recorded on a Varian 400 MHz NMR spectrometer. Molecular dynamic simulations were performed by adsorption locator module in Materials Studio 8.0 developed by Accelrys Inc.

Synthesis of 4-(1H-imidazo[4,5-f][1,10]phenanthrolin-2-yl)phenol (HIP-POH). The synthetic method was similar to the previous reported methods ${ }^{\mathrm{S} 1}$ in which the amount of chemicals was slightly different. A mixture of 1,10-phenanthroline-5,6-dione $(2 \mathrm{mmol}, 0.420 \mathrm{~g})$, p-hydroxybenzaldehyde ( $2 \mathrm{mmol}, 0.244 \mathrm{~g})$, ammonium acetate $(30 \mathrm{mmol}, 2.31 \mathrm{~g})$, and glacial acetic acid $(30 \mathrm{~mL})$ was heated under reflux with stirring for $2 \mathrm{~h}$. The cooled solution was diluted with $\mathrm{H}_{2} \mathrm{O}$ and neutralized with concentrated aqueous ammonia. The precipitate was collected and recrystallized from DMF to give yellow granular crystals.

${ }^{1} \mathrm{H}$ NMR (DMSO-d6, $)$ ): 13.31 (br. s, 1H), 9.72 (s, 1H), 9.05 (d, 2H), 8.92 (d, 2H), 8.13 (d, 2H), $7.73(\mathrm{dd}, 2 \mathrm{H}), 6.97(\mathrm{~d}, 2 \mathrm{H})$.

Synthesis of SCUN-1. A mixture of HIP-POH $(0.2 \mathrm{mmol}, 0.062 \mathrm{~g}), \mathrm{Cu}\left(\mathrm{NO}_{3}\right)_{2}(0.2 \mathrm{mmol}, 0.048$ g), $8.5 \mathrm{~mL}$ ethylene glycol, $7.5 \mathrm{~mL}$ deionized water and $2 \mathrm{~mL} \mathrm{HNO}_{3}(0.1 \mathrm{~mol} / \mathrm{L})$ was sealed in a Teflon lined stainless vessel $(25 \mathrm{~mL})$ and heated at $160{ }^{\circ} \mathrm{C}$ for $72 \mathrm{~h}$ under autogenous pressure, then cooled slowly to room temperature. Red block crystals were obtained (yield, $36 \mathrm{mg}, 52 \%$ based on HIP-POH).

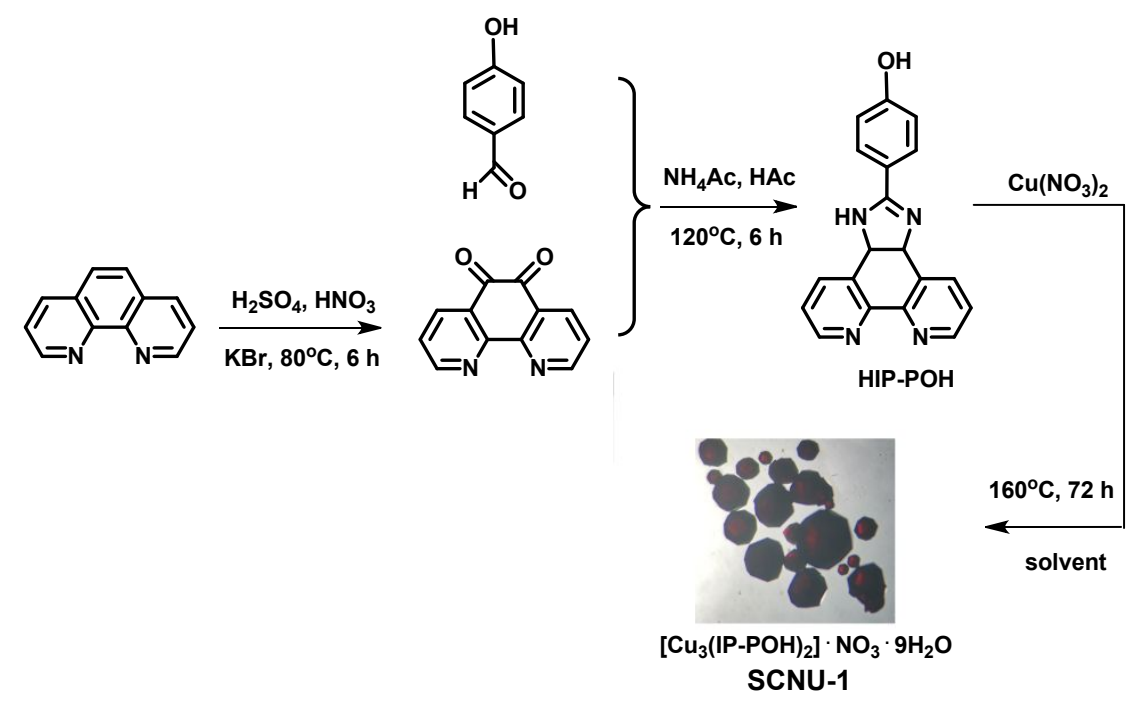

Scheme S1. The synthetic route of crystal product SCNU-1. 


\section{X-ray Crystallography}

The diffraction data were recorded in BL17B at Shanghai Synchrotron Radiation Facility (SSRF, Shanghai, China). The data were processed, integrated and scaled using HKL3000. Crystal data and structure refinements for SCNU-1 were deposited in CCDC (1919463) and summarized in Table S1.

Table S1. Crystal data and structure refinements for SCNU-1.

\begin{tabular}{|c|c|}
\hline & SCNU-1 (120 K) \\
\hline Empirical formula & $\mathrm{C}_{38} \mathrm{H}_{40} \mathrm{O}_{14} \mathrm{~N}_{9} \mathrm{Cu}_{3}$ \\
\hline$M$ & 1037.4 \\
\hline Crystal system & Cubic \\
\hline Space group & $I a-3 d$ \\
\hline $\mathrm{A}(\AA)$ & $41.456(5)$ \\
\hline $\operatorname{Vol}\left(\AA^{3}\right)$ & $71246(25)$ \\
\hline$Z$ & 48 \\
\hline$\rho_{\text {caldd }}\left(\mathrm{g} \mathrm{cm}^{-3}\right)$ & 1.163 \\
\hline$\mu\left(\mathrm{mm}^{-1}\right)$ & 1.092 \\
\hline reflns collected & 15480 \\
\hline unique reflns $\left(\mathrm{R}_{\mathrm{int}}\right)$ & $7968(0.0155)$ \\
\hline$S$ & 1.048 \\
\hline$R_{1}{ }^{[a]}, w R_{2}^{[b]}(I>2 \sigma(I))$ & $0.0530,0.1846$ (squeeze) \\
\hline$R_{1}{ }^{[a]}, w R_{2}^{[b]}$ (all data) & $0.0839,0.2138$ (squeeze) \\
\hline $\operatorname{Void}(\%)^{[c]}$ & $54.7 \%$ \\
\hline Pore volume $\left(\mathrm{cm}^{3} \mathrm{~g}^{-1}\right)^{[d]}$ & 0.47 \\
\hline \multicolumn{2}{|c|}{$[a] R_{1}=\sum|| F_{\mathrm{o}}|-| F_{\mathrm{c}} \| / \sum\left|F_{\mathrm{o}}\right|,{ }^{[b]} w R_{2}=\left[\sum w\left(F_{\mathrm{o}}^{2}-F_{\mathrm{c}}{ }^{2}\right)^{2} / \sum w\left(F_{\mathrm{o}}{ }^{2}\right)^{2}\right]^{1 / 2}$} \\
\hline \multicolumn{2}{|c|}{${ }^{[d]}$ Pore volume $=$ void $/ \rho_{\text {calcd }}$} \\
\hline
\end{tabular}




\section{Molecular Formula Determination}

Since the relatively low resolution obtained for SCNU-1, the guest molecules and counterions could not be determined by X-ray diffraction data. Therefore, the molecular formula of SCNU-1 was confirmed by IR (Figure S1), TG data (Figure 3a in text), elemental analyses (Table S2) and PXRD (Figure S8) of different treated samples. For IR spectra of SCNU-1, the peak at $1385 \mathrm{~cm}^{-1}$ indicated that the counterions contained $\mathrm{NO}_{3}{ }^{-}$. As shown in Figure 3a, the temperatures of weight loss in both as-synthesized and activated (at $373 \mathrm{~K}$ ) samples were similar in the range from 470 to $560 \mathrm{~K}$, indicating that the same substances decomposed at this condition. Furthermore, through caculation, the weight loss $(6 \%)$ in as-synthesized samples, corresponding to the loss of $\mathrm{HNO}_{3}$, were equal to the weight loss (7\%) in samples of activated at $373 \mathrm{~K}$ under vacuum. It was also confirmed by the TGA data of samples activated at $573 \mathrm{~K}$ under $\mathrm{N}_{2}$ atmosphere which showed no weight loss occured at that temperature region. All the samples were conducted with Elemental analysis. Finally, the guest molecules were concluded as nine water molecules.

$\mathrm{M}(813+\mathrm{x}) \times 7 \%=\mathrm{M}(813+\mathrm{x}+\mathrm{y}) \times 6 \%$

$\mathrm{y}=\mathrm{M}(813+\mathrm{x}+\mathrm{y}) \times 15 \%$

Here, $x$ and $y$ represented the molecular weight of counterions and guest molecules respectively. 813 was the molecular weight of framework of SCNU-1. Therefore, the results of $\mathrm{x}$ and $\mathrm{y}$ corresponded to be $63\left(1 \mathrm{HNO}_{3}\right)$ and $160\left(9 \mathrm{H}_{2} \mathrm{O}\right)$.

Table S2. Elemental analysis results for as-synthesized, activated and denitrified samples.

\begin{tabular}{lllllll}
\hline \multirow{2}{*}{ Samples } & \multicolumn{2}{c}{ Carbon, $\%$} & \multicolumn{3}{c}{ Hydrogen, \% } & \multicolumn{2}{c}{ Nitrogen, \% } \\
\cline { 2 - 7 } & Exp. & Calc. ${ }^{[a]}$ & Exp. & Calc. & Exp. & Calc. \\
\hline As-synthesized & 43.90 & 43.99 & 3.93 & 3.89 & 12.12 & 12.15 \\
Actived under 373 K & 51.74 & 52.14 & 2.59 & 2.53 & 14.29 & 14.40 \\
Denitrified under 573 K & 55.71 & 56.19 & 2.68 & 2.61 & 13.70 & 13.80 \\
\hline
\end{tabular}

${ }^{[a]}$ the formula used in calculation for different samples were listed as follow: As-synthesized, $\mathrm{Cu}_{3} \mathrm{C}_{38} \mathrm{H}_{40} \mathrm{O}_{14} \mathrm{~N}_{9}$; Actived under $373 \mathrm{~K}, \mathrm{Cu}_{3} \mathrm{C}_{38} \mathrm{H}_{22} \mathrm{O}_{5} \mathrm{~N}_{9}$; Denitrified under $573 \mathrm{~K}$, $\mathrm{Cu}_{3} \mathrm{C}_{38} \mathrm{H}_{21} \mathrm{O}_{2} \mathrm{~N}_{8}$.

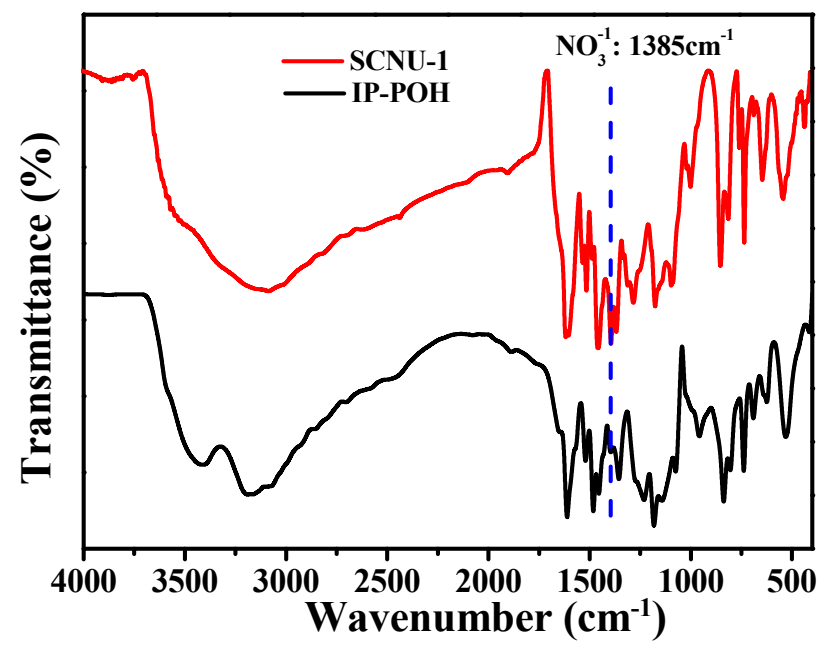

Figure S1. Infrared spectra of organic ligand (IP-POH) and as-synthesized SCNU-1. The peak appearing at $1385 \mathrm{~cm}^{-1}$ corresponds to $\mathrm{NO}_{3}^{-}$ions. ${ }^{\mathrm{S} 2}$ 


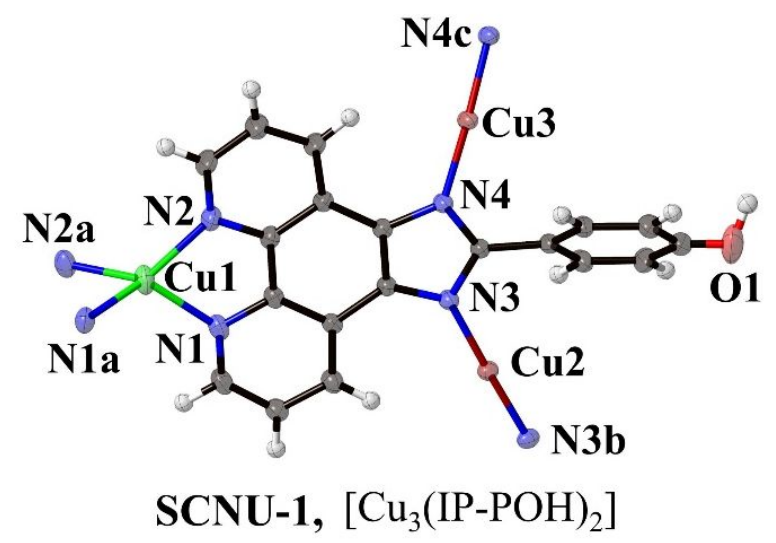

Figure S2. Coordination environments of the framework of SCNU-1 with $30 \%$ thermal ellipsoids $\left(\mathrm{NO}_{3}{ }^{-}\right.$and water molecules were omitted). Symmetry codes: a) $\left.y+1 / 4, x-1 / 4,-z+3 / 4 ; b\right)-x+3 / 2, y$, $-z+1 ; c)-x+5 / 4, z-1 / 4, y+1 / 4$.

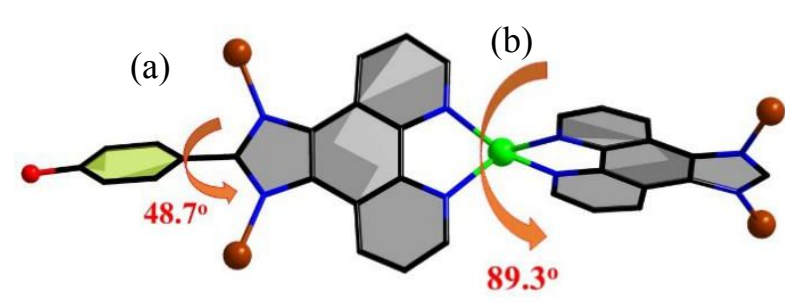

(c)

(d)

Figure S3. The structural details in SCNU-1, including rotation angle between phenyl ring and IP plane (a), rotation angle of two joined IP planes (b), and torsion angles of Cu3-N4-C13-N3 (c) and Cu2-N3-C13-N4 (d).

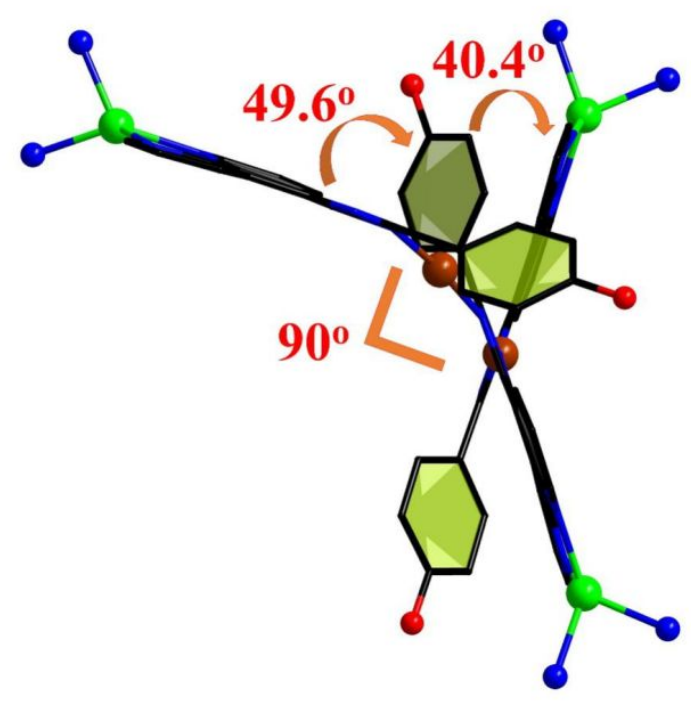

Figure S4. The dihedral angles of adjacent IP groups which are connected by $\mathrm{Cu} 2$ and $\mathrm{Cu} 3$ atoms are $40.4^{\circ}$ and $49.6^{\circ}$ respectively, therefore, three running IP groups are at right angle. 


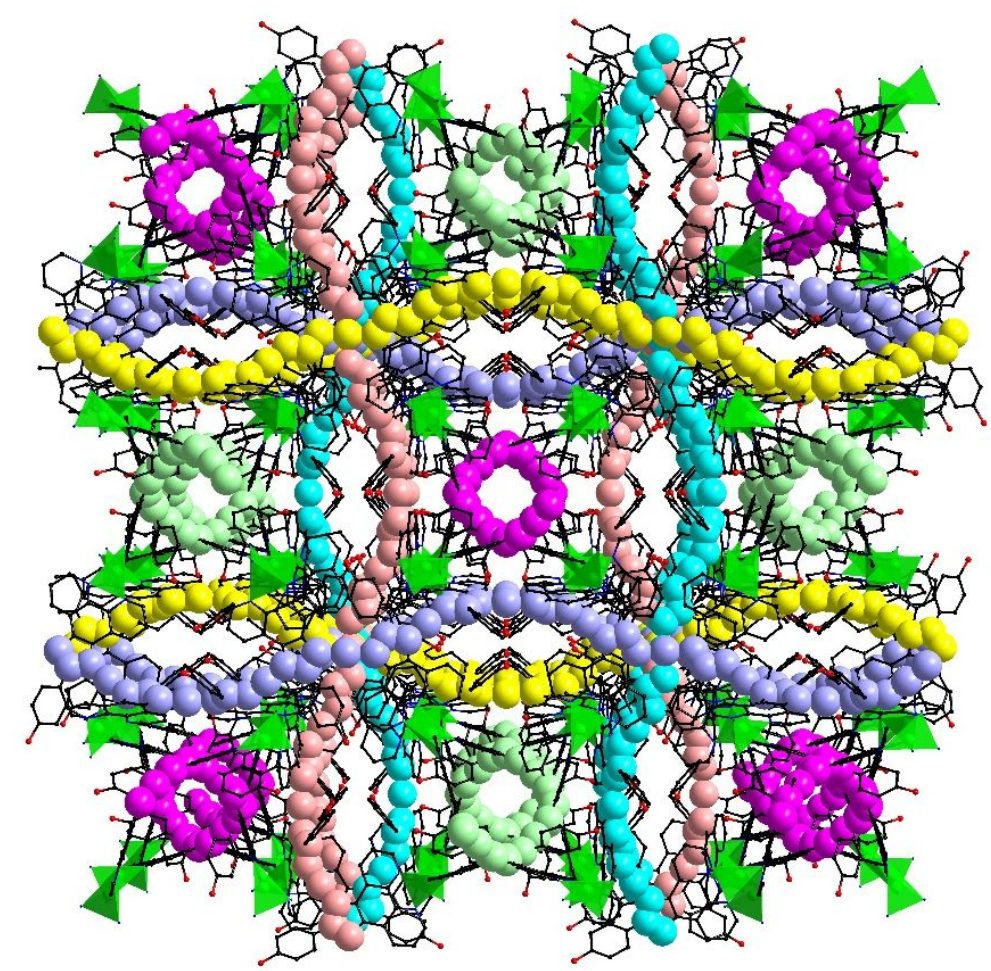

Figure S5. Perspective view of two-fold interpenetrated framework of SCNU-1 along $a$-axis.

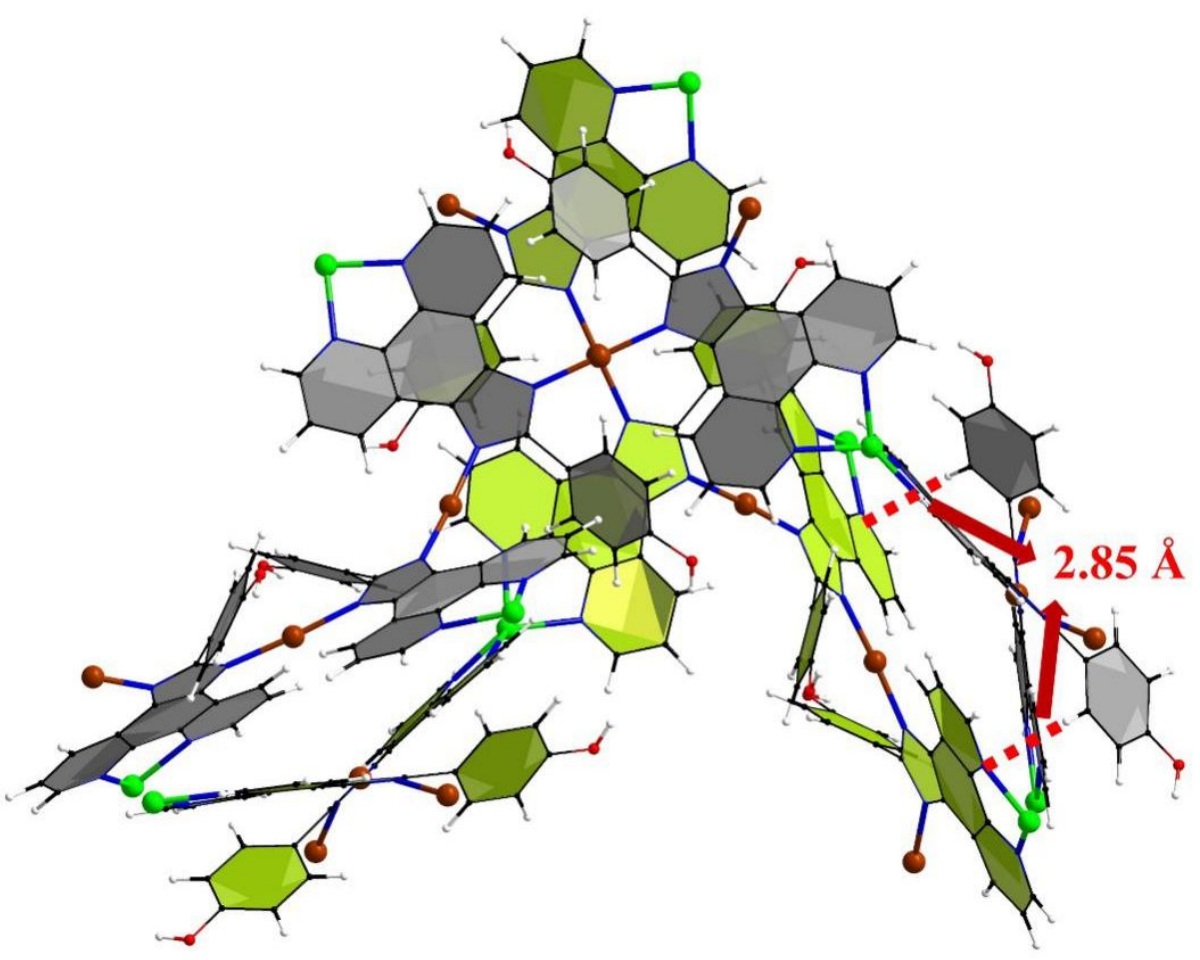

Figure S6. Perspective view of $\mathrm{C}-\mathrm{H} . . . \pi$ interaction in two interpenetrated frameworks (one framework is depicted as grey, the other one is yellow-green). 


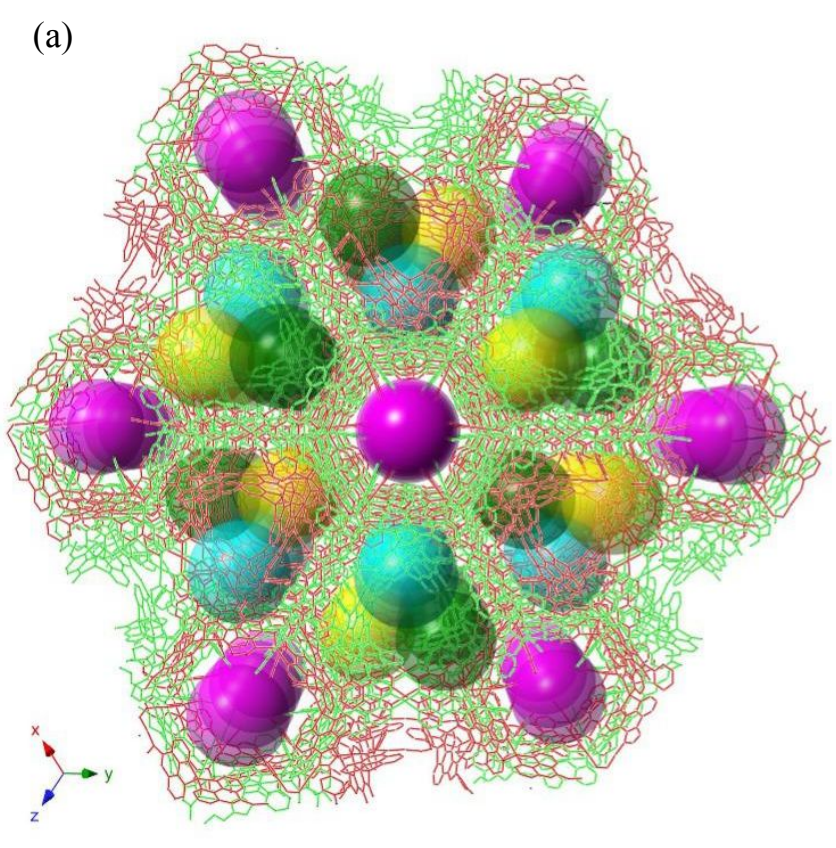

(b)
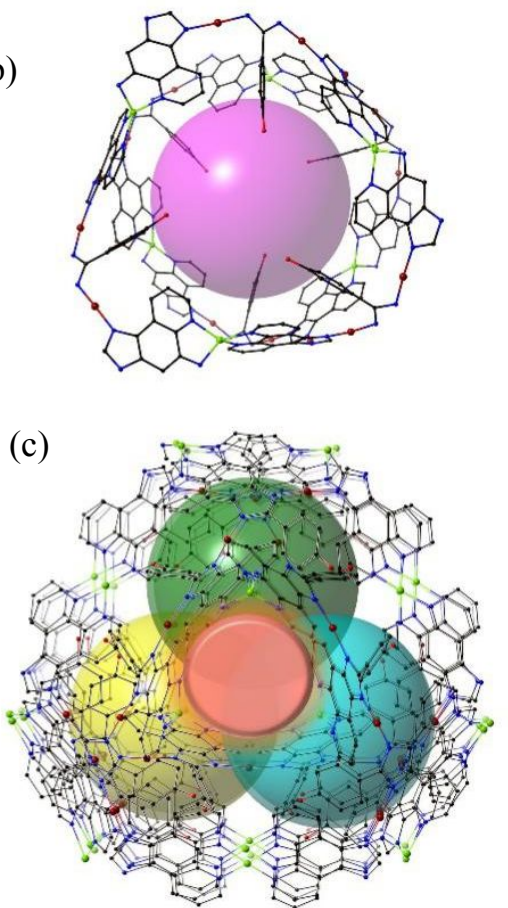

Figure S7. The perspective view of (a) interpenetrated 3D framework of SCNU-1 along (111) direction, (b) the spherical polyhedral cage and (c) 1D channel connecting three cages from three other directions.
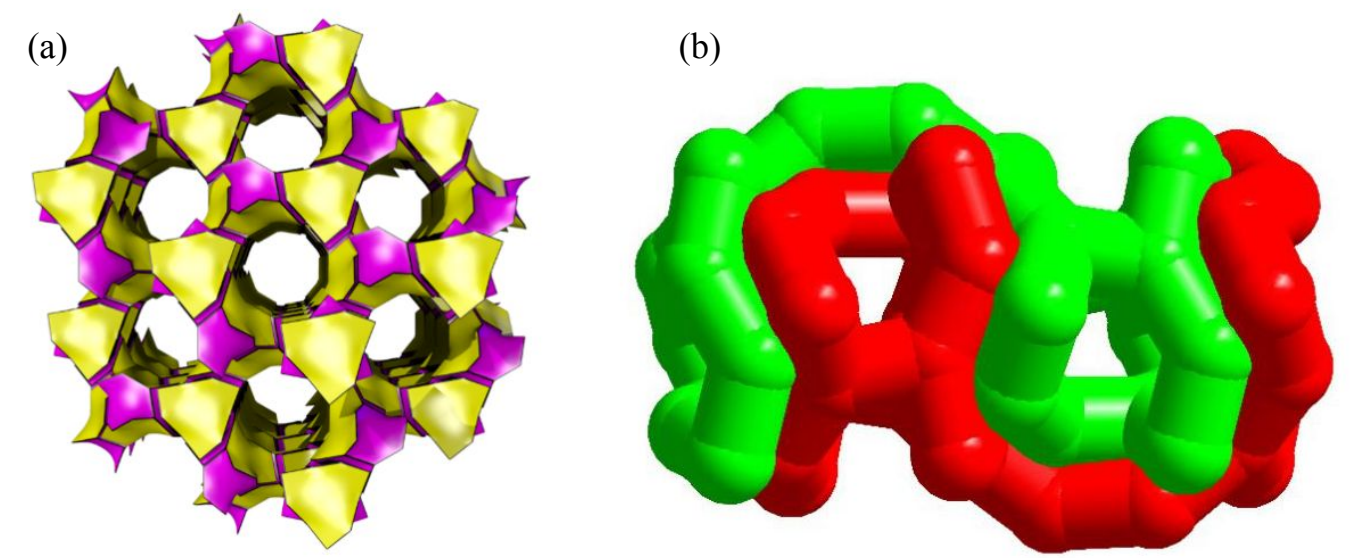

Figure S8. (a) The tiling view of right-handed utc network, (b) perspective view of G minimal surface formed at the interface of two utc networks in SCNU-1 
Thermal and Chemical Stabilities

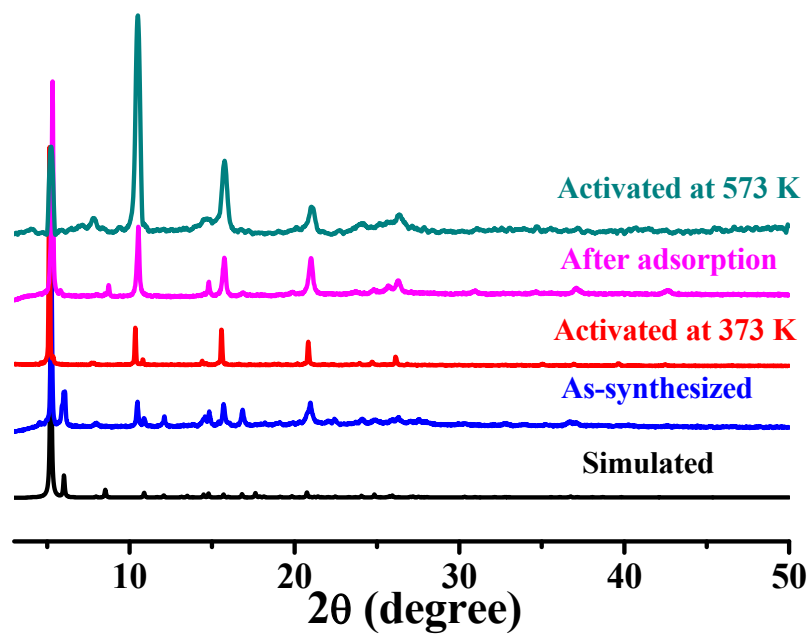

Figure S9. PXRD patterns of simulated, as-synthesized, activated and after gas sorption test.

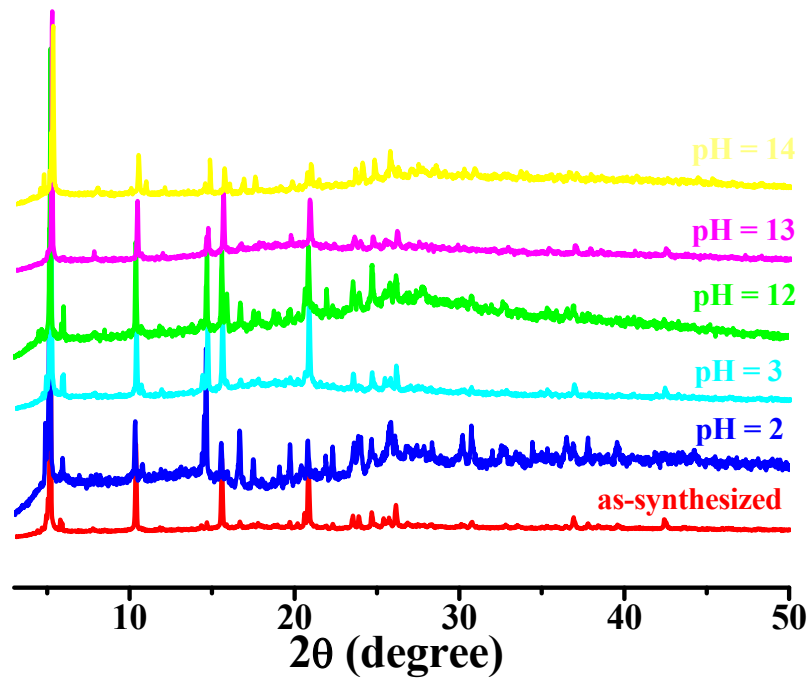

Figure S10. PXRD patterns of activated samples immersed in aqueous solutions of $\mathrm{HCl}$ and $\mathrm{NaOH}$ at different $\mathrm{pH}$ values ranging from 2 to 14 for $24 \mathrm{~h}$. 


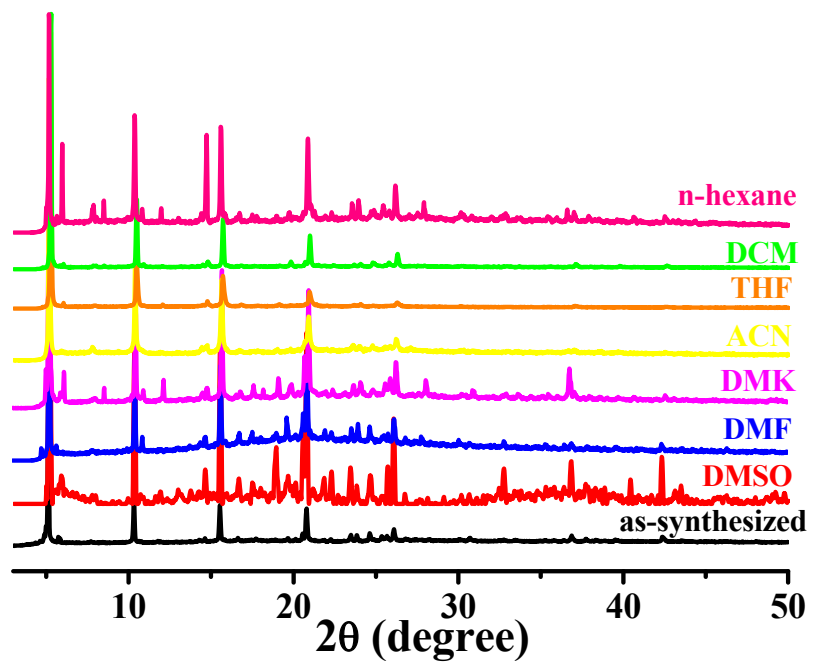

Figure S11. PXRD patterns of activated samples soaked in different organic solvents for $24 \mathrm{~h}$ (DMSO, dimethyl sulphoxide; DMF, Dimethylformamide; DMK, Acetone; ACN, Acetonitrile; THF, Tetrahydrofuran; DCM, dichloromethane).

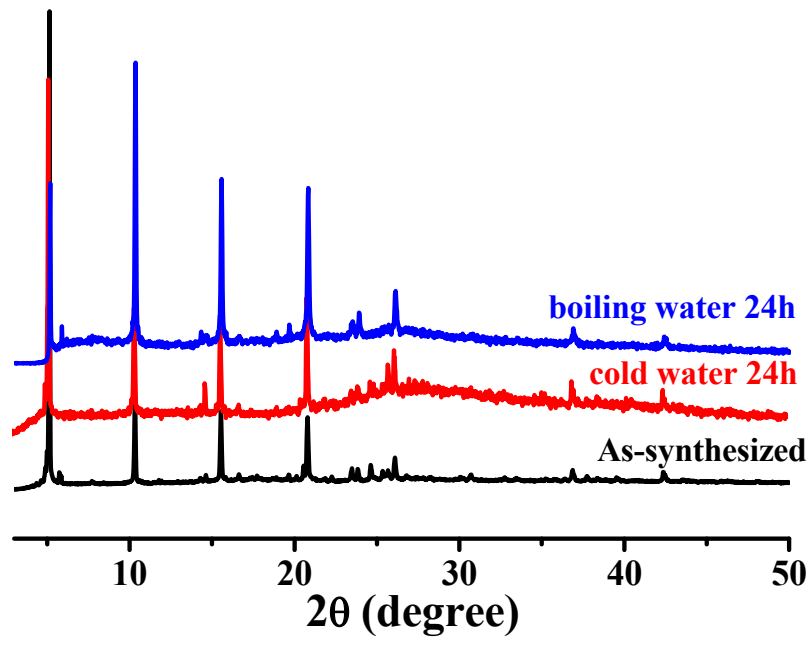

Figure S12. PXRD patterns of activated samples soaked in cold water and boiling water respectively for $24 \mathrm{~h}$.

It should be mentioned that the colour of crystals turn into green while they endured in solvents at room temperature for longer time ( $>3$ days). In contrast, the above experiments under $\mathrm{N}_{2}$ protection or the activated samples suspended into boiling water could maintain the crystallinity for 7 days. 


\section{Gas Adsorption Measurements}

Gas adsorption data for pressures in the range 0-1 bar were obtained by volumetric methods using a Micromeritics ASAP2020 Plus instrument. All gases were high purity (>99.99\%). Isotherm at $77 \mathrm{~K}$ was measured in liquid nitrogen baths. Isotherms at 273 and $298 \mathrm{~K}$ were measured using liquid circulators to maintain a constant temperature. The samples for SCNU-1 was activated at $373 \mathrm{~K}$ under dynamic vacuum for $2 \mathrm{~h}$ after exchanging guest molecules in $\mathrm{MeOH}$ solvent for 2 days.

\section{Isosteric Heat of Adsorption $\left(Q_{s t}\right)$ Calculations.}

Virial Method: virial-type expression comprising the temperature-independent parameters $a_{i}$ and $b_{i}$ was employed to calculate the enthalpies of adsorption for $\mathrm{CO}_{2}$ (at 273 and $298 \mathrm{~K}$ ) on SCNU-1. In each case, the data were fitted using the equation (1):

$$
\ln P=\ln N+1 / T \sum_{i=0}^{m} a_{i} N_{i}+\sum_{j=0}^{n} b_{i} N_{j}
$$

Here, $P$ was the pressure expressed in Torr, $N$ was the amount adsorbed in $\mathrm{mmol} / \mathrm{g}, T$ was the temperature in $\mathrm{K}, a_{i}$ and $b_{i}$ were virial coefficients, and $m, n$ represented the number of coefficients required to adequately describe the isotherms ( $m$ and $n$ were gradually increased until the contribution of extra added $a$ and $b$ coefficients was deemed to be statistically insignificant towards the overall fit, and the average value of the squared deviations from the experimental values was minimized). The values of the virial coefficients $a_{0}$ through am were then used to calculate the isosteric heat of adsorption using the following expression (2):

$$
Q_{s t}=-R \sum_{i=0}^{m} a_{i} N^{i}
$$

$Q_{s t}$ is the coverage-dependent isosteric heat of adsorption and $R$ is the universal gas constant. The heat of $\mathrm{CO}_{2}$ sorption for SCNU-1 in this manuscript is determined by using the excess sorption data measured in the pressure range from $0-800 \mathrm{mmHg}(273$ and $298 \mathrm{~K})$, which is fitted by the virial-equation very well $\left(\mathrm{R}^{2}>0.999\right)$.

DLS method: dual-site Langmuir equation (3) was also employed to model the $\mathrm{CO}_{2}$ adsorption at 273 and $298 \mathrm{~K}$ for SCNU-1 as a comparison.

$$
q=q_{1}+q_{2}=\frac{q_{\text {sat }, 1} b_{1} p}{1+b_{1} p}+\frac{q_{\text {sat }, 2} b_{2} p}{1+b_{2} p}
$$

where there are two distinct adsorption sites 1 and 2 .

Here, $q$ was molar loading of adsorbate expressed in $\mathrm{mol} / \mathrm{kg}, q_{\text {sat }}$ was saturation loading in $\mathrm{mol} / \mathrm{kg}, p$ was bulk gas phase pressure in $\mathrm{Pa}$, and $b$ was parameter in the pure component Langmuir adsorption isotherm, $\mathrm{Pa}^{-1}$.

The isosteric heat of adsorption, $Q_{s t}$, was calculated using

$$
Q_{s t}=R T^{2}\left(\frac{\partial \operatorname{Inp}}{\partial T}\right)_{q}
$$

Here $Q_{s t}$ is the coverage-dependent isosteric heat of adsorption and $R$ is the universal gas constant. 
Prediction of the Gases Adsorption Selectivity by IAST. The ideal adsorbed solution theory (IAST) calculation predicted the adsorption selectivity from the experimental pure gas isotherms. The partial pressures of $\mathrm{CO}_{2}$ and $\mathrm{N}_{2}$ were 0.15 and 0.85 bar respectively, which was a typical composition for flue gas from power plant. To begin with, the adsorption isotherms of $\mathrm{CO}_{2}$ and $\mathrm{N}_{2}$ were fitted by the Langmuir-Freundlich (5) model to allow the application of IAST in simulating the performance of the samples under mixed component gas.

$$
N=\frac{A_{1} b_{1} p^{c 1}}{1+b 1 p^{c 1}}
$$

Here $p$ is pressure of bulk gas at equilibrium with adsorbed phase (bar), $N$ is molar loading of adsorbate ( $\mathrm{mmol} / \mathrm{g}), A_{1}$ is saturation or maximum loading ( $\left.\mathrm{mmol} / \mathrm{g}\right), b$ is affinity coefficient $\left(\mathrm{bar}^{-1}\right)$ and $c 1$ is adsorbate-adsorbent interaction (surface heterogeneity) parameter.

We employed the fitting parameter for the prediction of multi-component adsorption with IAST. The adsorption selectivities, $S_{1 / 2}$, in a binary mixture is explained as $\left(x_{1} / x_{2}\right) /\left(y_{1} / y_{2}\right)$, where $x_{i}$ is the molar fraction of species $i$ in the adsorbed phase and $y_{i}$ is the molar fraction of species $i$ in the bulk phase.

$$
S_{1 / 2}=\left(\frac{x_{1}}{x_{2}}\right)\left(\frac{y_{2}}{y_{1}}\right)
$$




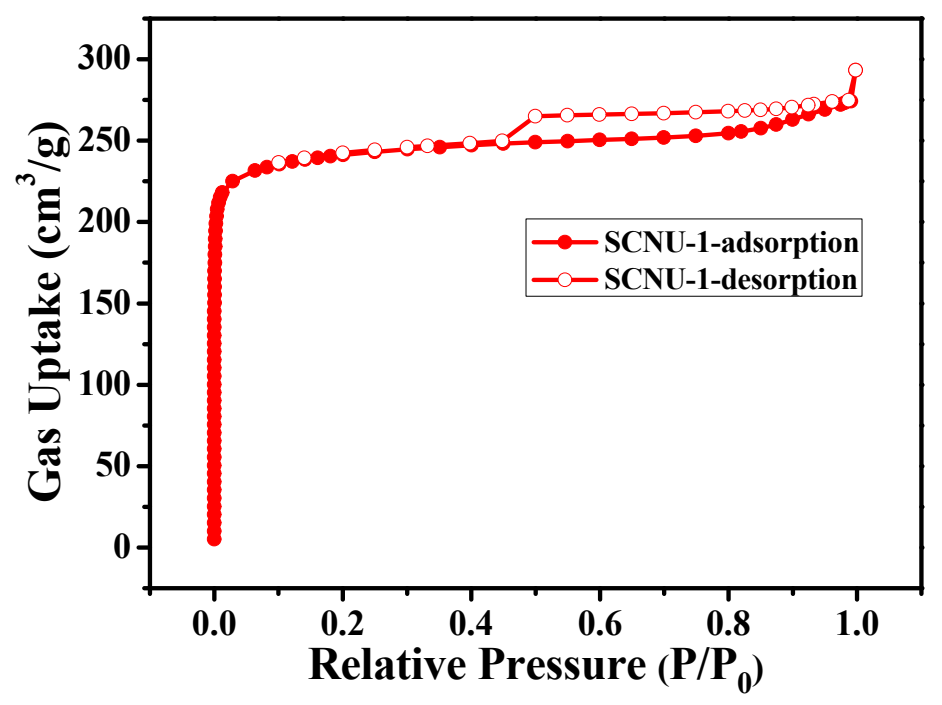

Figure S13. The N2 sorption isotherm of SCNU-1 at $77 \mathrm{~K}$.
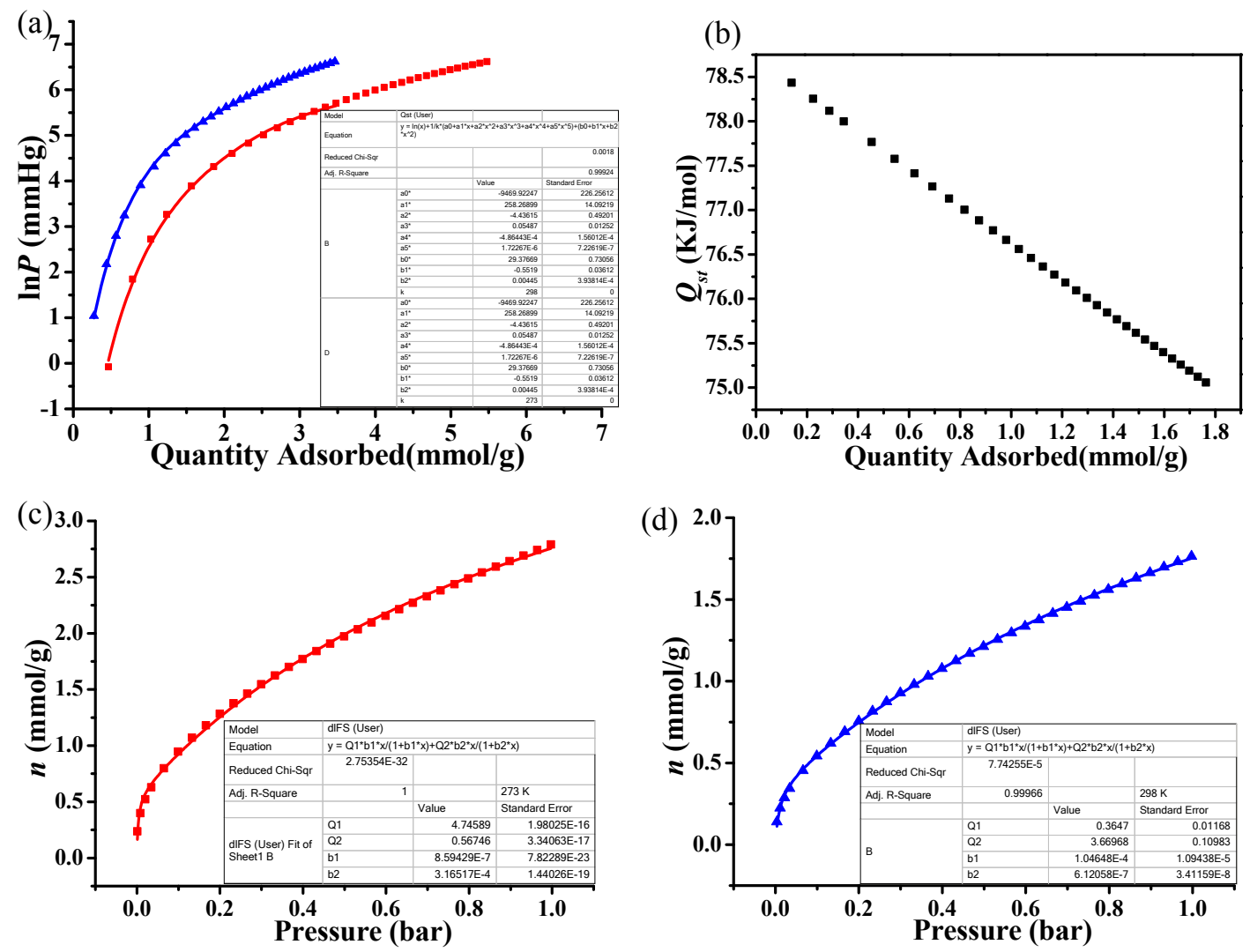

Figure S14. (a) Virial fitting (lines) in the adsorption range of $0-3.5 \mathrm{mmol} / \mathrm{g}$ for the $\mathrm{CO}_{2}$ adsorption isotherms (points) of SCNU-1 measured at 273 (red) and $298 \mathrm{~K}$ (blue). (b) Coverage-dependent $\mathrm{CO}_{2}$ adsorption enthalpy obtained by Virial method. Dual-site Langmuir fitting (lines) of the $\mathrm{CO}_{2}$ adsorption isotherms (points) of SCNU-1 measured at 273 (c) and $298 \mathrm{~K}$ (d). 

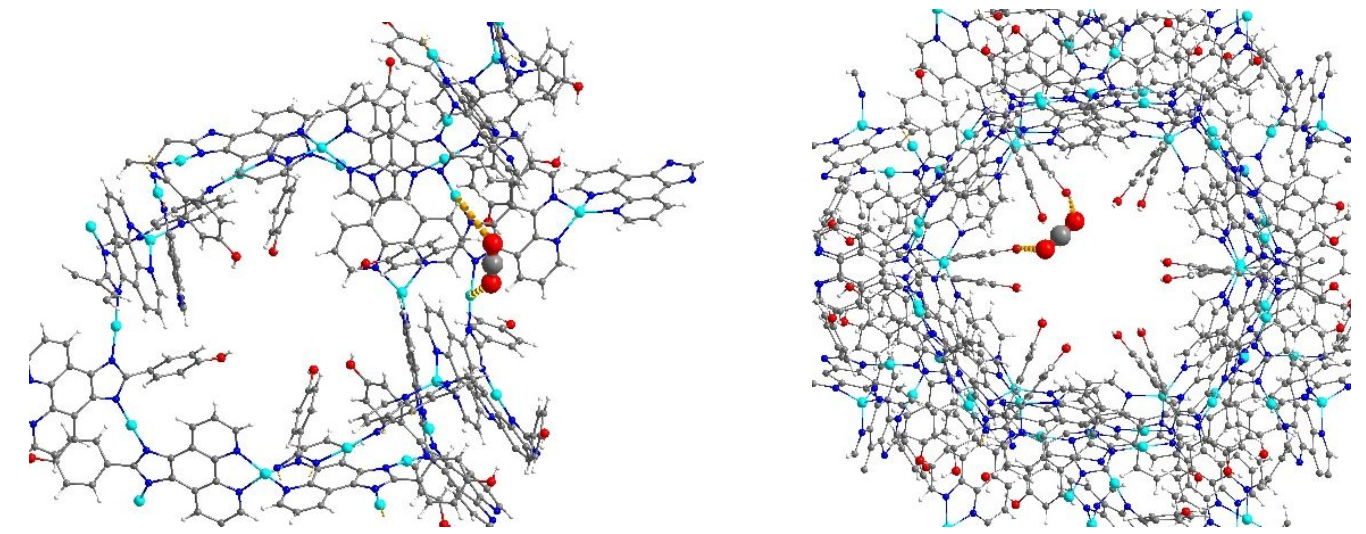

Figure S15. Two optimized adsorption sites for $\mathrm{CO}_{2}$ molecules in the pore of SCNU-1.

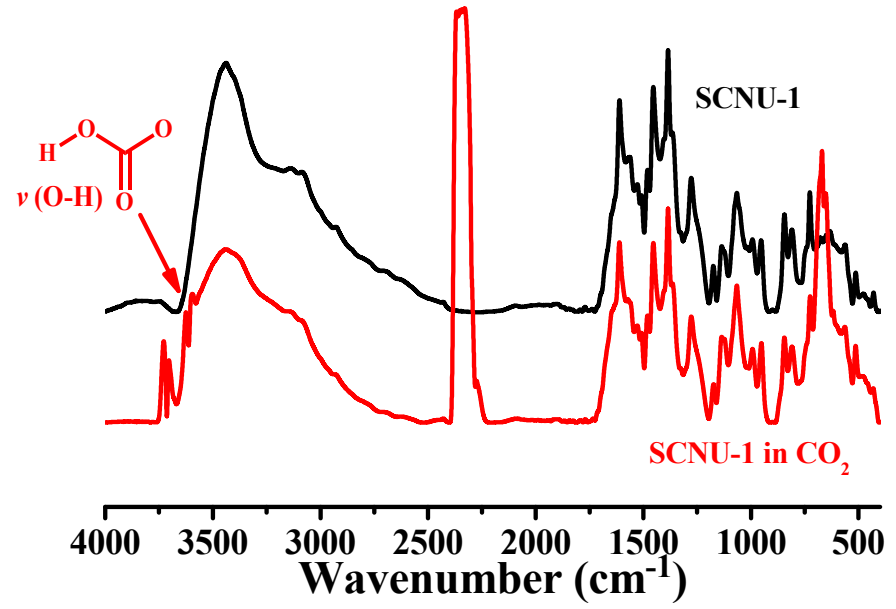

Figure S16. In situ IR spectra of SCNU-1 in different atmospheres. 
Table S3. Comparison of the $\mathrm{CO}_{2}$ adsorption performances of selected MOFs with hydroxyl groups.

\begin{tabular}{|c|c|c|c|c|}
\hline Compound (common name) & $\begin{array}{c}Q_{s t} \\
(\mathrm{KJ} / \mathrm{mol})\end{array}$ & Selectivity & Functional groups & Ref \\
\hline SCUN-1 & $78^{a} / 90^{b}$ & $108^{d}$ & & $\begin{array}{l}\text { This } \\
\text { work }\end{array}$ \\
\hline Mg-MOF-74 & $42^{b}$ & $148^{e}$ & & $27 \mathrm{c}$ \\
\hline MFM-305 & $40^{a}$ & $48^{d}$ & Al-OH and pyridyl & S3 \\
\hline HKUST-1 & $35^{c}$ & $101^{d}$ & OMS & $27 \mathrm{a}$ \\
\hline UiO-66(Zr)-(OH $)_{2}$ & $33^{b}$ & $105^{d}$ & & $27 b$ \\
\hline UTSA-15a & $41^{a}$ & - & & S4 \\
\hline CPM-74 & $33^{b}$ & $77^{f}$ & & S5 \\
\hline$\left[\mathrm{Zn}_{4}(M e-\mathrm{TPC} 4 \mathrm{R})\left(\mathrm{L}^{2}\right)_{4}\right] \cdot 3 \mathrm{DMF} \cdot \mathrm{H}_{2} \mathrm{O}$ & $33^{a}$ & - & & S5 \\
\hline CTOF-1 & $32^{a}$ & - & & S6 \\
\hline MAC-4-OH & $31^{a}$ & - & & S7 \\
\hline CPM-142 & $28^{c}$ & - & & S8 \\
\hline IRMOF-9-OH & $28^{a}$ & - & & S9 \\
\hline LIFM-32 & $27^{a}$ & $18^{d}$ & & S10 \\
\hline HHU-4 & $24^{a}$ & - & & S11 \\
\hline AlOF-1 & $20^{a}$ & $108^{g}$ & Al-OH & $\mathrm{S} 12$ \\
\hline
\end{tabular}

${ }^{a}$ Obtained by the Virial fitting method.

${ }^{b}$ Obtained by the Clausius-Clapeyron equation and dual-site Langmuir fitting.

${ }^{c}$ Obtained by the Clausius-Clapeyron equation without mathematical fitting.

${ }^{d}$ Calculated using IAST in the molar ratio of $\mathrm{CO}_{2} / \mathrm{N}_{2}=15: 85$ at 1 bar and $298 \mathrm{~K}$.

${ }^{e}$ Calculated using IAST in the molar ratio of $\mathrm{CO}_{2} / \mathrm{N}_{2}=15: 75$ at 1 bar and $323 \mathrm{~K}$.

${ }^{f}$ Calculated using IAST in the molar ratio of $\mathrm{CO}_{2} / \mathrm{N}_{2}=10: 90$ at 1 bar and $298 \mathrm{~K}$.

${ }^{g}$ Calculated using IAST in the molar ratio of $\mathrm{CO}_{2} / \mathrm{N}_{2}=15: 85$ at 1 bar and $283 \mathrm{~K}$.

OMS: open metal sites.

PSP: pore space partition. 


\section{Reference:}

S1. J.-Z. Wu, L. Li, T.-X. Zeng, L.-N. Ji, J.-Y. Zhou, T. Luo and R.-H. Li. Polyhedron, 1997, 16, 103.

S2. K. Nakamoto, Infrared and Raman Spectra of Inorganic and Coordination Compounds; 6th ed.; John Wiley and Sons, Inc., New Jersey, 2009.

S3. L. Li, I. da Silva, D. I. Kolokolov, X. Han, J. Li, G. Smith, Y. Cheng, L. L. Daemen, C. G. Morris, H. G. W. Godfrey, N. M. Jacques, X. Zhang, P. Manuel, M. D. Frogley, C. A. Murray, A. J. Ramirez-Cuesta, G. Cinque, C. C. Tang, A. G. Stepanov, S. Yang and M. Schroder, Post-synthetic modulation of the charge distribution in a metal-organic framework for optimal binding of carbon dioxide and sulfur dioxide. Chem. Sci., 2019, 10, 1472-1482.

S4. Z. Chen, S. Xiang, H. D. Arman, J. U. Mondal, P. Li, D. Zhao, B. Chen, Three-Dimensional Pillar-Layered Copper(II) Metal-Organic Framework with Immobilized Functional OH Groups on Pore Surfaces for Highly Selective $\mathrm{CO}_{2} / \mathrm{CH}_{4}$ and $\mathrm{C}_{2} \mathrm{H}_{2} / \mathrm{CH}_{4}$ Gas Sorption at Room Temperature. Inorg. Chem. 2011, 50, 3442-3446.

S5. H. Yang, F. Peng, C. Dang, Y. Wang, D. Hu, X. Zhao, P. Feng, X. Bu, Ligand Charge Separation To Build Highly Stable Quasi-Isomer of MOF-74-Zn. J. Am. Chem. Soc. 2019, 141, 9808-9812.

S5. W.-Y. Pei, G. Xu, J. Yang, H. Wu, B. Chen, W. Zhou, J.-F. Ma, Versatile Assembly of Metal-Coordinated Calix[4]resorcinarene Cavitands and Cages through Ancillary Linker Tuning. J. Am. Chem. Soc. 2017, 139, 7648-7656.

S6. K. Hong, W. Bak, D. Moon, H. Chun, Bistable and Porous Metal-Organic Frameworks with Charge-Neutral acs Net Based on Heterometallic $\mathrm{M}_{3} \mathrm{O}\left(\mathrm{CO}_{2}\right)_{6}$ Building Blocks. Cryst. Growth Des. 2013, 13, 4066-4070

S7. Y. Ling, F. Yang, M. Deng, Z. Chen, X. Liu, L. Weng, Y. Zhou, Novel Iso-Reticular Zn(II) Metal-Organic Frameworks constructed by Trinuclear-Triangular and Paddle-Wheel Units: Synthesis, Structure and Gas Adsorption. Dalton Trans. 2012, 41, 4007-4011

S8. Q.-G. Zhai, X. Bu, C. Mao, X. Zhao, L. Daemen, Y. Cheng, A. J. Ramirez-Cuesta, P. Feng, An ultra-tunable platform for molecular engineering of high-performance crystalline porous materials. Nat. Commun. 2016, 7, 13645.

S9. I. Spanopoulos, P. Xydias, C. D. Malliakas, P. N. Trikalitis, A Straight Forward Route for the Development of Metal - Organic Frameworks Functionalized with Aromatic - OH Groups: Synthesis, Characterization, and $\mathrm{Gas}\left(\mathrm{N}_{2}, \mathrm{Ar}, \mathrm{H}_{2}, \mathrm{CO}_{2}, \mathrm{CH}_{4}, \mathrm{NH}_{3}\right)$ Sorption Properties. Inorg. Chem. 2013, 52, 855-862.

S10. C.-X. Chen, Z. Wei, J.-J. Jiang, Y.-Z. Fan, S.-P. Zheng, C.-C. Cao, Y.-H. Li, D. Fenske, C.-Y. $\mathrm{Su}$, Precise Modulation of the Breathing Behavior and Pore Surface in Zr-MOFs by Reversible Post-Synthetic Variable-Spacer Installation to Fine-Tune the Expansion Magnitude and Sorption Properties. Angew. Chem. Int. Ed. 2016, 55, 9932-9936

S11. Z. Lu, Y. Xing, L. Du, H. He, J. Zhang, C. Hang, Isostructural functionalization by $-\mathrm{OH}$ and $-\mathrm{NH}_{2}$ : different contributions to $\mathrm{CO}_{2}$ adsorption. $R S C A d v$. 2017, 7, 47219-47224. 
S12. J. Qian, J. Shen, Q. Li, Y. Hu and S. Huang, Selective adsorption behaviour of carbon dioxide in $\mathrm{OH}$-functionalized metal-organic framework materials. CrystEngComm, 2017, 19, 5346-5350. 